\title{
Maternal recognition of pregnancy
}

\author{
W. W. Thatcher, M. D. Meyer and G. Danet-Desnoyers \\ Department of Dairy and Poultry Sciences, Institute of Food and Agricultural Sciences, \\ University of Florida, Gainesville, FL 32611. USA
}

\begin{abstract}
Enhanced secretion of $\mathrm{PGF}_{2 u}$ from endometrial explants in vitro in response to oxytocin is associated with augmented activities of phospholipase $A_{2}$, phospholipase $\mathrm{C}$ and prostaglandin endoperoxide $\mathrm{H}$ synthase (PGS). In early pregnancy, maintenance of the corpus luteum is associated with an absence of pulsatile $\mathrm{PGF}_{20}$ secretion; an increase in endometrial inhibitors of phospholipase $A_{2}$ and PGS contribute to the antiluteolytic alterations of $\mathrm{PGF}_{2 \alpha}$ secretion. Linoleic acid is a competitive inhibitor of arachidonic acid metabolism by PGS, and microsomal concentrations of free linoleic acid are increased in the endometrium of pregnant cattle. The trophoblast produces large quantities of interferon tau (IFN- $\tau$ ). Inhibition of increases in endometrial oestradiol receptor mRNA and protein are associated with intrauterine administration of recombinant ( $r$ ) ovine (o) IFN- $\tau$ in sheep. Intrauterine injections of rbovine (b) IFN- $\tau$ in cattle (days 14-17) altered endometrial function so that secretion of $\mathrm{PGF}_{2 \alpha}$ from cultured endometrial epithelial cells was reduced. Antiluteolytic effects were not expressed in $20 \%$ of cows receiving IFN- $\tau$ or $r b I F N-\alpha_{1} I$ indicating that an inadequate endometrial responsiveness may contribute to embryo mortality. IFN- $\tau$ may activate a signal transduction system similar to that induced by other type I IFNs; activation of an intracellular tyrosine kinase ultimately leads to activation of an IFN-stimulated response element to induce gene transcription. Biological responses associated with pregnancy and IFN- $\tau$ treatment are integrated into a multifactorial antiluteolytic model. Strategies to enhance embryo survival could include supplementation with rIFN- $\tau$ and alterations in endometrial responsiveness to this cytokine through dietary manipulation of lipid metabolism.
\end{abstract}

\section{Introduction}

Maternal recognition of pregnancy can be considered as the interaction between the maternal unit and products of conception that signals to the mother the need to maintain pregnancy. This dialogue can occur at various critical stages during pregnancy, but one critical process in ruminants involves paracrine regulation by the conceptus of the underlying endometrium that leads to an attenuation of luteolytic PGF $_{2 a}$ secretion. This antiluteolytic effect of the conceptus (Thatcher et al., 1986) is the primary cause of maintenance of the corpus luteum in sheep and cattle and is the focus of this review. An understanding of the antiluteolytic process depends on a clear comprehension of the mechanisms regulating endometrial $\mathrm{PGF}_{2 u}$ secretion during the luteal and luteolytic phases of the oestrous cycle. With this understanding, the potential pathways by which interferon- $\tau$ (IFN- $\tau$ ) acts on the endometrium can be elucidated and potential strategies implemented to improve embryo survival.

\section{Mechanisms Regulating Endometrial $\mathrm{PGF}_{2 a}$ Secretion}

The limiting factors controlling $\mathrm{PGF}_{2 \alpha}$ secretion are the availability of arachidonic acid and the rate of $\mathrm{PGF}_{20}$ formation by prostaglandin endoperoxide $\mathrm{H}$ synthase (PGS). After a period of progesterone 
priming, low amplitude pulses of $\mathrm{PGF}_{2 \alpha}$ occur in both cyclic and pregnant sheep (Silvia et al., 1984) and cattle (Parkinson and Lamming, 1990). After these initial increases in PGF secretion, large terminal pulses of $\mathrm{PGF}_{2 \pi}$ develop in the cyclic animal that cause the final stages of regression of the corpus luteum. Endometrial oxytocin receptors are induced in the latter stages of the oestrous cycle of sheep and cattle, and there is a positive feedback loop between uterine PGF $_{2 \alpha}$ and luteal oxytocin secretion (Flint et al., 1986). Accordingly, a major focus of investigation has been the oxytocin signal transduction system that leads to enhanced $\mathrm{PGF}_{2 a}$ secretion. A major second messenger system receiving intensive investigation in both species (Flint et al., 1986; Silvia and Raw, 1993; Lafrance and Goff, 1990) has been the oxytocin-induced increase in phospholipase C (PLC) activity leading to the metabolism of phosphatidylinositol bisphosphate to inositol triphosphate $\left(\mathrm{IP}_{3}\right)$ and diacylglycerol (DAG). These intracellular messengers can contribute to enhanced PGF $_{2 \alpha}$ secretion by enhancing $\mathrm{PLA}_{2}$ activity (for example increased intracellular $\mathrm{Ca}^{2+}$ ), providing an additional source of arachidonic acid via the metabolism of DAG by DAG lipases, or through the action of protein kinase $C$ after activation by DAG (Lafrance and Goff, 1990). However, a series of recent investigations (Silvia and Raw, 1993; Silvia et al., 1994; Lee and Silvia, 1994) have disassociated to some degree the responsiveness of the PLC signal transduction system from the oxytocin-induced stimulation of PGF in ovine endometrium. For example, endometrial tissue from cyclic sheep on days 12, I4 and 16 displayed a clear oxytocin-induced increase in $\mathrm{PGF}_{2 a}$ secretion, whereas PLC activity did not increase in response to oxytocin until day 14 (Silvia and Raw, 1993). An additional study compared the dose-dependent effect of oxytocin on PLC activity and $\mathrm{PGF}_{2 n}$ secretion in endometrial tissue from ovariectomized ewes treated with steroids to mimic luteal and follicular changes in the oestrous cycle (Silvia et al., 1994). The dose of oxytocin required to increase PLC activity was ten times that required to stimulate $\mathrm{PGF}_{20}$ secretion. Collectively, these findings indicate that the stimulatory effects of oxytocin on secretion of $\mathrm{PGF}_{20}$ are mediated through mechanisms other than phosphatidylinositol-specific PLC.

Lee and Silvia (1994) used endometrial tissues from ovariectomized ewes receiving steroid replacement to permit oxytocin-induced increases in $\mathrm{PGF}_{2 i}$ secretion and demonstrated that a stimulator of $\mathrm{PLA}_{2}$ (melittin) enhanced $\mathrm{PGF}_{2 a}$ secretion comparable to that induced by oxytocin. Furthermore, aristolochic acid (an inhibitor of PLA $\mathrm{P}_{2}$ ) blocked the increase in $\mathrm{PGF}_{2 \alpha}$ secretion induced by oxytocin and melittin. Inhibition of PLA $\mathrm{A}_{2}$ activity did not block the oxytocin-induced increase in PLC activity or the ability of arachidonic acid to enhance $\mathrm{PGF}_{20}$ secretion. Thus, oxytocin appears to act through an intracellular mechanism proximal to $\mathrm{PLA}_{2}$ to stimulate $\mathrm{PGF}_{2 \text { if }}$ secretion. The potential PLA $\mathrm{A}_{2}$ intracellular pathway, in addition to the latter stage responses of PLC, appears to be regulating $\mathrm{PGF}_{2 a}$ secretion during the pre- and luteolytic periods. These pathways and the regulation of PGS activity are likely candidates for antiluteolytic regulation during early pregnancy.

\section{Regulatory Effects of Pregnancy on PGF $_{2 a}$ Secretion}

It is well documented that the dynamics of $\mathrm{PGF}_{2 \alpha}$ secretion are altered in early pregnancy of sheep and cattle compared with comparable stages of the oestrous cycle (see reviews of Thatcher et al, 1986 and Geisert et al., 1994). Alterations in $\mathrm{PGF}_{2 \alpha}$ secretion have been documented experimentally by monitoring differences between cyclic and pregnant animals in transitory patterns of $\mathrm{PGF}_{2 \alpha}$ secretion and oestradiol or oxytocin-induced alterations in $\mathrm{PGF}_{2 \alpha}$ secretion. It is clear that the luteolytic patterns of $\mathrm{PGF}_{2 \alpha}$ secretion are attenuated in early pregnancy. Furthermore, there is a slight species difference in the pattern of $\mathrm{PGF}_{2 \alpha}$ secretion during pregnancy. In cows, luteolytic pulses are abolished without a major increase in basal secretion of $\mathrm{PGF}_{2 \alpha^{\prime}}$ whereas, in sheep, numbers of luteolytic $\mathrm{PGF}_{3 \alpha}$ pulses are reduced but basal secretion of $\mathrm{PGF}_{2 \pi}$ is actually enhanced in early pregnancy.

Several recent reports have documented differences in lipid metabolism and intracellular regulatory pathways of endometrial tissue from cyclic and pregnant animals. In a comparison of endometrial PLA $A_{2}$ activity between early pregnant and cyclic ewes on days 12,14 and 16, PLA 2 activity was decreased on day 14 and day 16 of pregnancy (Tamby et al., 1993). Furthermore, endometrial homogenates from ewes at day 16 of pregnancy exerted a greater inhibition of pancreatic PLA $A_{2}$ activity than did homogenates 
from cyclic ewes. In endometrial tissue of pregnant sheep (days 12, 14 and 16), oxytocin induction of PLC activity was absent (Silvia and Raw, 1993). However, oxytocin and arachidonic acid could induce $\mathrm{PGF}_{2 a}$ secretion at these times. Thus, the stimulatory effects of oxytocin appear to be manifested in a manner other than that involving phosphatidylinositol-specific PLC. The stimulatory effect of arachidonic acid may signify that arachidonic acid availability is limiting in tissues of pregnancy. This would be consistent with a decrease in endometrial PLA $A_{2}$ activity during early pregnancy in sheep (Tamby et al., 1993).

Addition of $\mathrm{Ca}^{2+}$ to the medium enhanced basal $\mathrm{PGF}_{2 u}$ secretion of endometrial tissue from both cyclic and pregnant cattle at day 17 after oestrus, in both groups (Thatcher et al., 1992). Further addition of exogenous $\mathrm{PLA}_{2}$ markedly enhanced basal secretion of $\mathrm{PGF}_{2 \omega}$ in explants from pregnant but not from cyclic cows. Also, addition of arachidonic acid caused a marked stimulation of $\mathrm{PGF}_{2 a}$ secretion in both groups; however, the response was considerably less in explants from pregnancy. Thus, availability of arachidonic acid may be limiting basal secretion of $\mathrm{PGF}_{2 \alpha}$ in early pregnancy of cows. Alternatively, an inhibitor of PGS may also be present in early pregnancy.

Thatcher et al. (1985) postulated that the antiluteolytic effect of the conceptus may be mediated by the induction of an intracellular molecule in endometrial tissue that inhibited the enzymatic conversion of arachidonic acid to $\mathrm{PGF}_{2 \alpha}$. Studies using assays that monitored the ability of microsomes to convert arachidonic acid to $\mathrm{PGF}_{2 a}$ (determination by radioimmunoassay or conversion of radiolabelled arachidonic acid to $\mathrm{PGF}_{20}$ as monitored by HPLC) showed that an endometrial prostaglandin synthesis inhibitor was present in bovine endometrium and that its activity was enhanced during pregnancy (Gross et al,, 1988; Danet-Desnoyers et al., 1993). The EPSI presumably acted on PGS since both $\mathrm{PGF}_{2 \alpha}$ and $\mathrm{PGE}_{2}$ were inhibited. EPSI was originally thought to be a protein (Gross et al., 1988), but it is now known that EPSI is a lipophilic molecule(s) that can co-elute with BSA during purification (Danet-Desnoyers et al., 1993; Thatcher et al., 1994). Lipid extraction followed by thin layer chromatography has revealed that EPSI activity migrates in the free fatty acid class. Separation of free fatty acids by HPLC resulted in the active component being highly enriched in linoleic acid, a fatty acid shown previously to inhibit PGS activity (Elattar and Lin, 1989). Thus, linoleic acid is probably one of the molecules responsible for EPSI activity. Furthermore, linoleic acid was found to act as a competitive inhibitor towards PGS when added to the bovine microsome assay (Thatcher et al., 1994). Thus, it is feasible that the conceptus alters lipid metabolism in the endometrium leading to increased availability of linoleic acid, inhibition of PGS activity, and decreased synthesis of $\mathrm{PGF}_{2 \alpha}$. G. Danet-Desnoyers and W. W. Thatcher (unpublished observations) measured PGS inhibitory activity and amounts of free linoleic and arachidonic fatty acids in endometrial microsomes of cyclic $(n=3)$ and pregnant $(n=4)$ cows at day 17 after oestrus. Units of PGS inhibitory activity were greater in microsomes prepared from pregnant than from cyclic cows (Fig. 1). Lipids from microsomes were extracted with chloroform and methanol ( $1: 2)$. The chloroform phase was subjected to thin layer chromatography (hexane, ethyl ether and acetic acid [80:20:1 by volume]) to isolate free fatty acids. After extraction of free fatty acids from the TLC plate with chloroform:methanol (95:5), the free fatty acids were methylated and fatty acid methyl esters separated and quantified by gas chromatography. The total amounts of unesterified linoleic and arachidonic acids in microsomal fractions were expressed as $\mathrm{ng} \mathrm{mg}^{-1}$ protein. Endometrial microsomes from pregnant cows had higher linoleic acid concentrations and lower arachidonic acid concentrations than did cyclic cows (Fig. 1). Consequently, the ratio of linoleic to arachidonic acids was higher in microsomes of pregnant cows. On the basis of the concentration of linoleic acid found in the microsomes and the inhibitory activity of linoleic acid in the PGS inhibition assay, all of the difference in PGS inhibitory activity between microsomes of cyclic and pregnant cows can be accounted for by the differences in linoleic acid concentrations. The reduced concentration of free arachidonic acid in the microsomal fraction also supports the possibility that arachidonic acid may

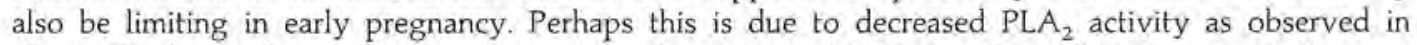
sheep (Tamby et al, 1993). Gene expression of endometrial PGS (2.8 Kb mRNA transcript) does not appear to be regulated by the conceptus (Salamonsen ef al., 1991). However, data concerning PGS indicators indicate that PGS is altered by endogenous endometrial inhibitors of enzymatic activity involved in prostaglandin biosynthesis. 


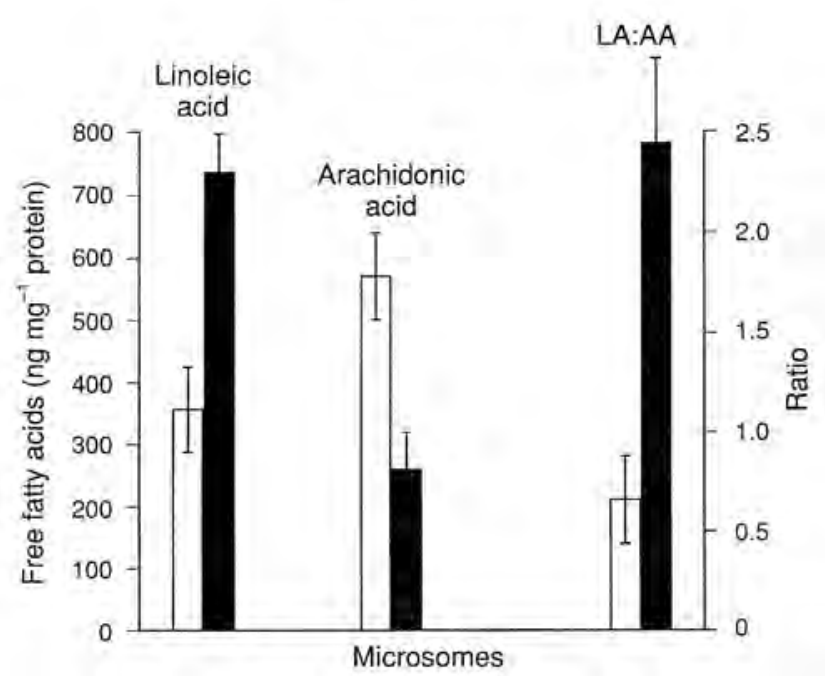

Fig. 1. Concentrations of free linoleic (LA) and arachidonic acids (AA), and their ratios in endometrial microsomes of cyclic ( $\square)$ and pregnant ( cows at day 17 after oestrus.

\section{Effects of Interferon- $\tau$ on Uterine Function In Vivo and In Vitro}

It is well recognized that conceptuses of sheep and cattle produce an antiluteolytic interferon that alters uterine secretion of $\mathrm{PGF}_{2 \alpha}$ and thereby contributes to maintenance of the corpus luteum and continuation of pregnancy (Bazer, 1992). Roberts et al. (1992) recommended a nomenclature of interferon tau (IFN- $\tau$ ) for the ruminant trophoblastic interferons because these proteins have a high sequence identity to each other (as opposed to other type I interferons; $\alpha, \beta$, and $\omega$ ) and are poorly induced by viruses. In situ hybridization with specific probes for mRNAs encoding oIFN- $\tau$ and bIFN- $\tau$ indicate that expression occurs at the time conceptuses begin to elongate and that localization is confined to the trophectoderm (Roberts et al, 1992). Increased secretion occurs with growth of ovine and bovine conceptuses from spherical to tubular to filamentous forms, In both species, increased secretion of olFN- $\tau$ and bIFN- $\tau$ occurs before the equivalent time of luteolysis in cyclic animals. The role of the uterus to enhance secretion of bIFN- $\tau$ was demonstrated clearly by Hernandez-Ledezma et al. (I992). Embryos that were produced by in vitro maturation-in vitro fertilization (IVM-IVF) expressed and secreted bIFN- $\tau$ at the blastocyst stage of development. However, secretion of bIFN- $\tau$ in oifro was very limited in extended culture. In contrast, when morula or blastocysts from IVM-IVF were transferred to the uteri of synchronized cows and recovered 4 days later, hatched blastocysts secreted copious amounts of IFN- $\tau$ in extended culture. Clearly, induction of IFN- $\tau$ is regulated developmentally but amplification and sustained secretion require exposure to the uterine environment. Imakawa ef al. (1993) demonstrated the presence of granulocyte-macrophage colony-stimulating factor (GM-CSF) in the luminal and glandular epithelium of the uterine endometrium of sheep. Expression and secretion of IFN- $\tau$ was enhanced when day 17 ovine conceptus tissues were cultured with GM-CSF. However, the effect of GM-CSF depended upon dose, and the GM-CSF is probably not responsible for the large secretion of IFN- $\tau$.

Recombinant forms of bIFN- $\tau$ (Klemann et al, 1990) and oIFN- $\tau$ (Ott et al, 1991; Charlier et al, 1989; Martal et al., 1990) elicit biological responses that are indistinguishable from IFN- $\tau$ purified from conceptuses. We have recently tested the effect of intrauterine injections of bIFN- $\tau$ and oIFN- $\tau$ on lifespan of the corpus luteum, interoestrous interval and oxytocin-induced uterine secretion of PGF $2 \alpha$ (Meyer et al., in press). Cows received intrauterine injections of rolFN- $\tau(n=4 ; 100 \mu \mathrm{g})$ plus BSA $(1.4 \mathrm{mg})$ or BSA alone $(n=5 ; 1.5 \mathrm{mg})$ in Expt 1 and $\mathrm{rbIFN}-\tau(n=6 ; 200 \mu \mathrm{g})$ plus BSA $(1.3 \mathrm{mg})$ or BSA alone $(n=5 ; 1.5 \mathrm{mg})$ in Expt 2 . Beginning on day 14 of the experimental oestrous cycle, cows received twice daily injections $(07: 00 \mathrm{~h}$ and 19:00 h) split evenly between the uterine horns via an AI pipette in Expt 1 and via intrauterine catheters, surgically placed on day 10 of the oestrous cycle, in Expt 2 . Blood 


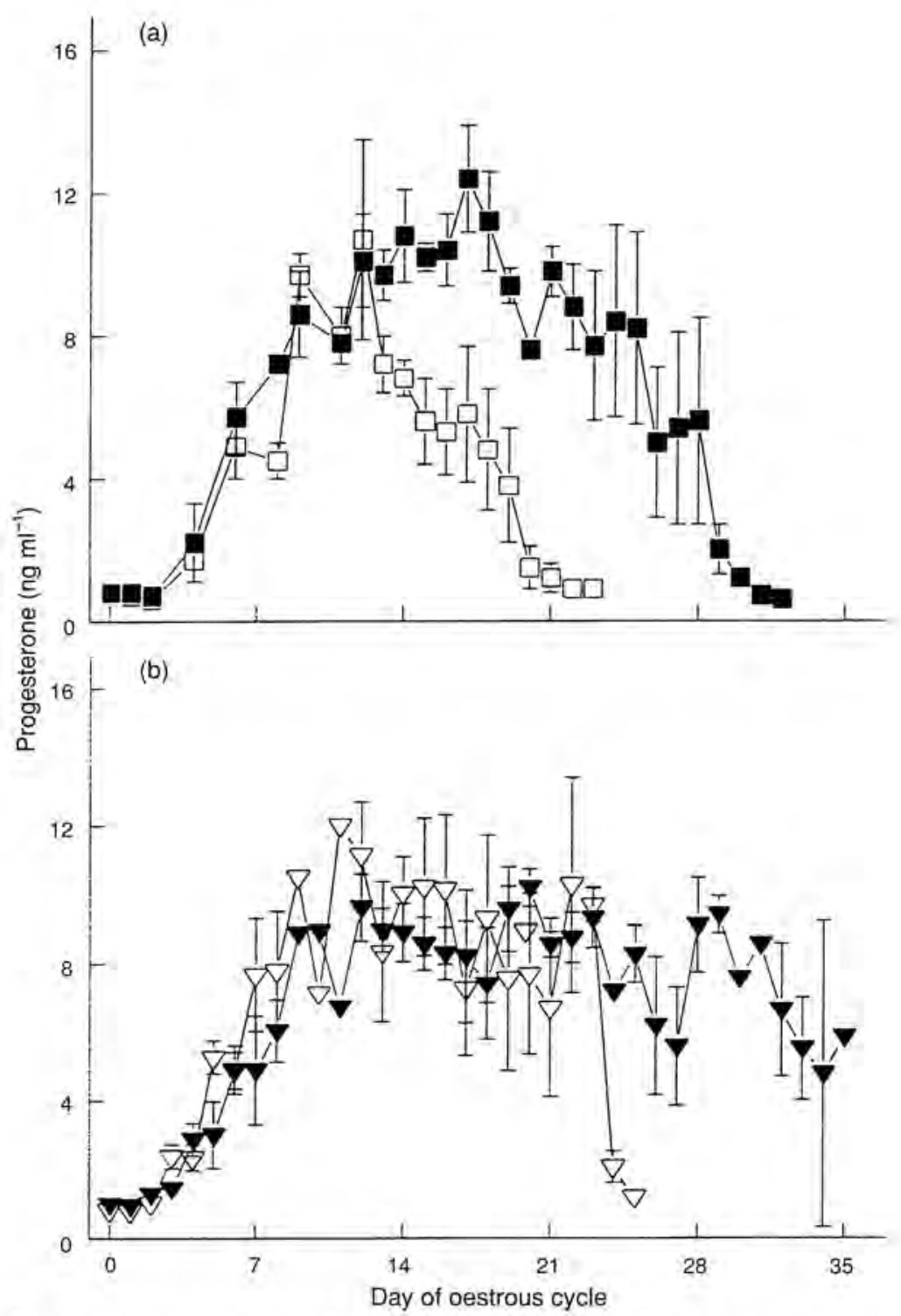

Fig. 2. Plasma progesterone (mean \pm sEM) of cattle infused with (a) recombinant ovine interferon $\tau$ (rolFN- $\tau$ ) $(\mathbf{Q})$ or BSA $(\square)$ and (b) rbIFN- $\tau(\boldsymbol{\nabla})$ or BSA $(\nabla)$ from day 14 to day 24 of the oestrous cycle.

was collected daily and assayed for progesterone to determine the lifespan of the corpus luteum. Injections were continued until day 24 after oestrus or until return to oestrus. On day 17 after oestrus, all cows were injected i.v. with 100 units oxytocin, and plasma collected at $15 \mathrm{~min}$ intervals for $2 \mathrm{~h}$

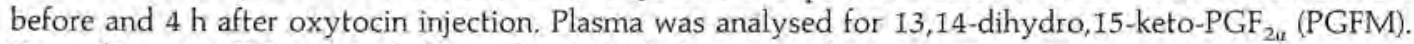
Recombinant oIFN $-\tau$ extended the lifespan of the corpus luteum $(27.5 \pm 1.2$ versus $19.2 \pm 1.2$ days; $P<0.01$; Fig. $2 \mathrm{a})$ and interoestrous interval $(30.5 \pm 0.9$ versus $20.6 \pm 0.8$ days; $P<0.01$ ). Recombinant bIFN $-\tau$ also extended the lifespan of the corpus luteum $(29.0 \pm 2.2$ versus $21.4 \pm 2.4$ days; $P<0.05$; Fig. $2 b)$ and interoestrous interval $(31.5 \pm 2.2$ versus $22.6 \pm 2.5$ days; $P<0.05)$. Treatment with roIFN $-\tau$ (Fig. 3a) and rbIFN- $\tau$ (Fig. 3b) attenuated the oxytocin-induced increase in plasma PGFM (Fig. 3). 


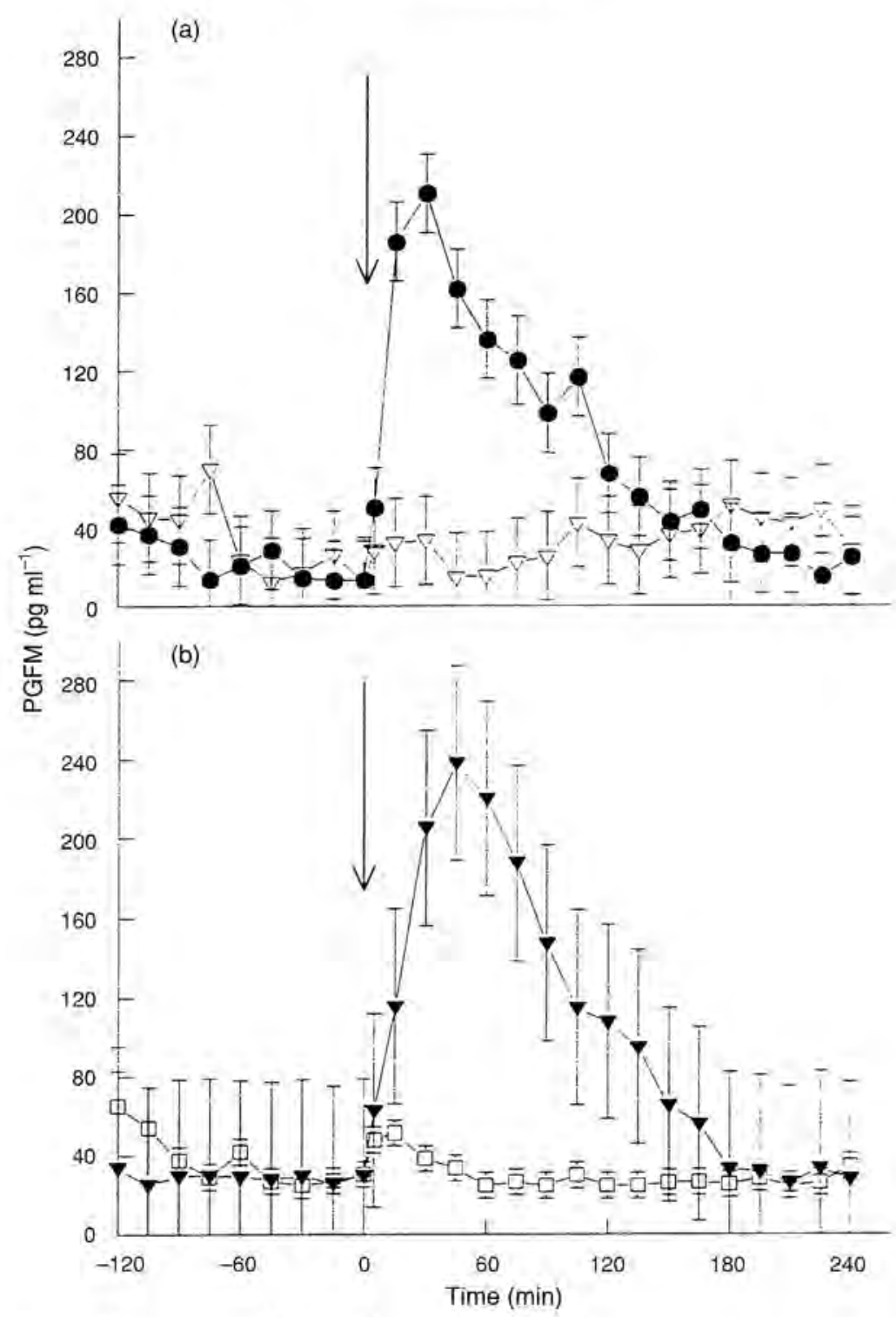

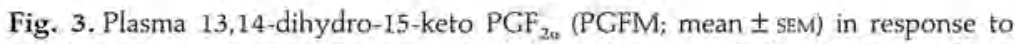
100 iu oxytocin (arrows) on day 17 of the oestrous cycle for (a) BSA (-) or rolFN- $\tau(\nabla)$ treatment groups in Expt 1 and (b) BSA $(\mathbf{\nabla})$ or rblFN $\tau(\square)$ treatment groups in Expt 2.

These results indicate that both roIFN- $\tau$ and rbIFN- $\tau$ are effective antiluteolytic agents that can extend corpus luteum function and inhibit oxytocin-induced secretion of uterine $\mathrm{PGF}_{2 \alpha}$ in cattle. However, it is important to indicate that significant variability between animals in the lifespan of the corpus luteum (24-29 days for roIFN- $\tau$ and $27-35$ days in rbIFN- $\tau$ ) and responsiveness to oxytocin were detected in response to both IFN- $\tau$ treatments (Fig. $4 \mathrm{~b}, \mathrm{~d}$ ). This type of animal variability is evident in previous studies with rolFN- $\tau$ in sheep (Martal et al., 1990) and native bIFN- $\tau$ in cattle (Helmer et al., 1989). It raises the possibility that responsiveness to IFN- $\tau$ may vary markedly depending on uterine response mechanisms associated with receptor kinetics or efficiency of intracellular post-receptor cell signalling. 

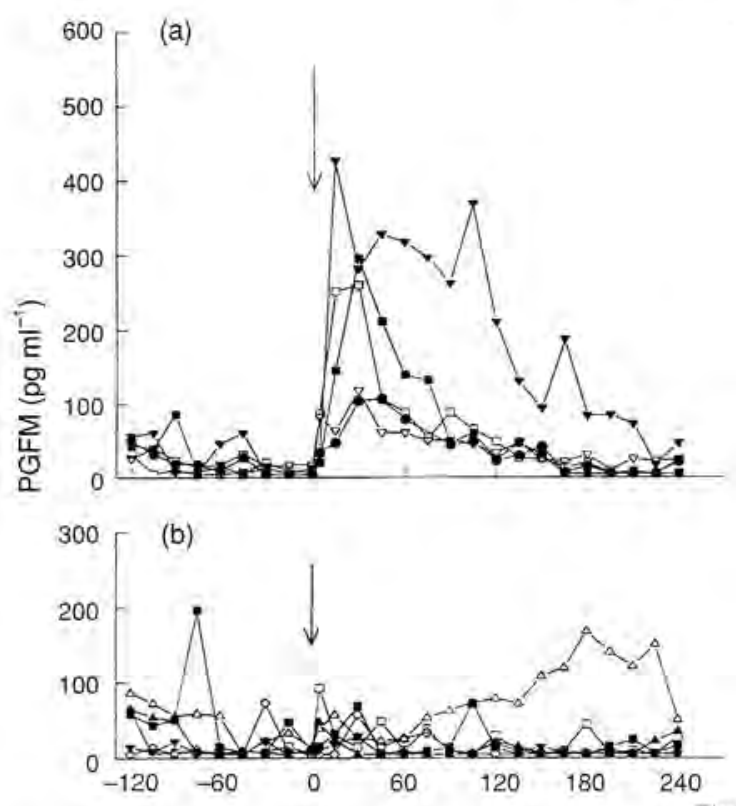

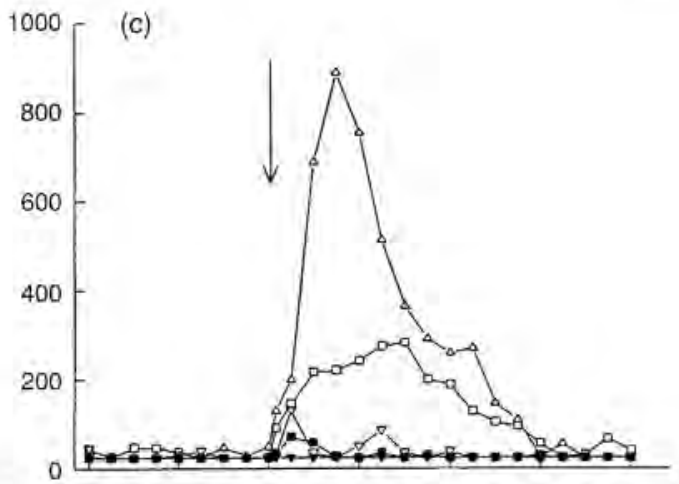

(d)

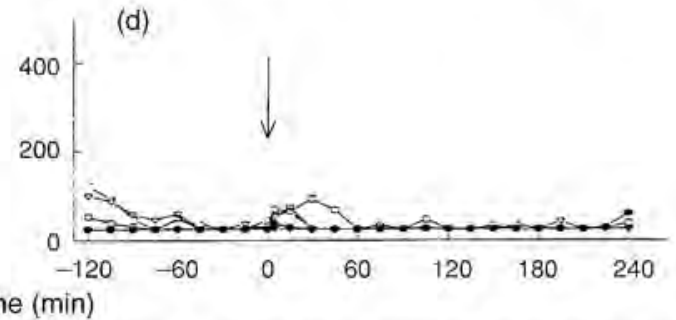

Fig. 4. Individual plasma 13,14-dihydro-15-keto PGF $_{20}$ (PGFM) profiles for cows in (a) BSA or (b) recombinant.

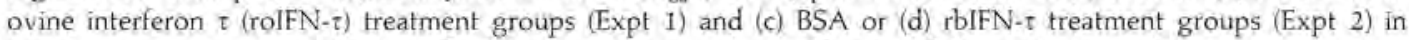
response to intravenous injection of 100 iu oxytocin (arrows) on day 17 of the oestrous cycle.

The ability of native and recombinant bIFN- $\tau$ to attenuate basal and oxytocin-induced secretion of $\mathrm{PGF}_{2 \mathrm{a}}$ by primary cultures of bovine endometrial epithelial cells from cyclic cows at day 15 of the oestrous cycle further documents the paracrine regulatory potential of the trophectoderm (Danet-Desnoyers et al., 1994). A 50\% inhibition of basal and oxytocin-induced secretion of PGF $_{2 a}$ and $\mathrm{PGE}_{2}$ from epithelial cells was obtained with a dose of $I \mathrm{ng} \mathrm{ml} \mathrm{m}^{-1}$. This is a concentration that is within the reported ranges for $K_{\mathrm{d}}$ value estimates for oIFN- $\tau$ receptors in sheep endometrial tissue. The inhibition of prostaglandin secretion appears to be cell specific since $\mathrm{PGF}_{2 \mu}$ and $\mathrm{PGE}_{2}$ secretion by stromal cells was not altered by either IFN- $\tau$ or oxytocin.

We recently evaluated the effect of treatment with rbIFN- $\tau$ in oivo on endometrial oxytocin receptor concentrations and $\mathrm{PGF}_{20}$ secretion from endometrial epithelial cells in vitro (Meyer et al., 1994). Beginning on day 14 of the oestrous cycle, cows received twice daily (07:00 h and 19:00 h) injections (via intrauterine catheters) of $200 \mu \mathrm{g}$ rbIFN- $\tau$ plus $1.3 \mathrm{mg}$ BSA or $1.5 \mathrm{mg}$ BSA divided equally between the two uterine horns ( $\mathrm{rbIFN}-\tau$ group, $n=5$; BSA control group, $n=5$ ), Injections were continued until 07:00 h on day 17 and cows were slaughtered at 10:00 h on day 17 to recover reproductive tracts. Uterine horns were assigned randomly (ipsilateral versus contralateral to corpus luteum) for collection of endometrium for cell culture or oxytocin receptor determination. Endometrial epithelial cells were isolated from both treatment groups for culture as described elsewhere (Danet-Desnoyers et al., 1994). Epithelial cells were treated at confluency with 0,2 or $50 \mathrm{ng}$ rbIFN- $\tau \mathrm{ml}^{-1}$. After $24 \mathrm{~h}$ of rbIFN- $\tau$ treatment, cells received oxytocin $\left(2 \times 10^{-7} \mathrm{~mol}^{-1} \mathrm{l}\right)$ and medium was sampled 0,30 and $90 \mathrm{~min}$ later for analysis of $\mathrm{PGF}_{20}$. Oxytocin receptors were measured in endometrial membranes using a receptor assay validated with endometrial tissue from cows in oestrus $\left(K_{d}=2.08 \times 10^{-9} \mathrm{~mol} \mathrm{l}^{-1}\right.$; $B_{\max }=2.135 \mathrm{pmol} \mathrm{mg}^{-1}$ protein).

Oxytocin receptor binding (percentage specific binding per $100 \mu \mathrm{g}$ protein) was low in both treatments but slightly attenuated in the rbIFN $-\tau$ treatment group $(0.30<0.60 \pm 0.07 \%, P<0.05)$. Although this treatment difference was detected, binding was low compared with the $35 \%$ specific binding for endometrium collected at oestrus. Secretion of $\mathrm{PGF}_{2 \alpha}$ was affected by an interaction between in vivo treatment with rbIFN- $\tau$ and in vitro rbIFN- $\tau$ treatment and oxytocin (Fig. 5). Treatment with 


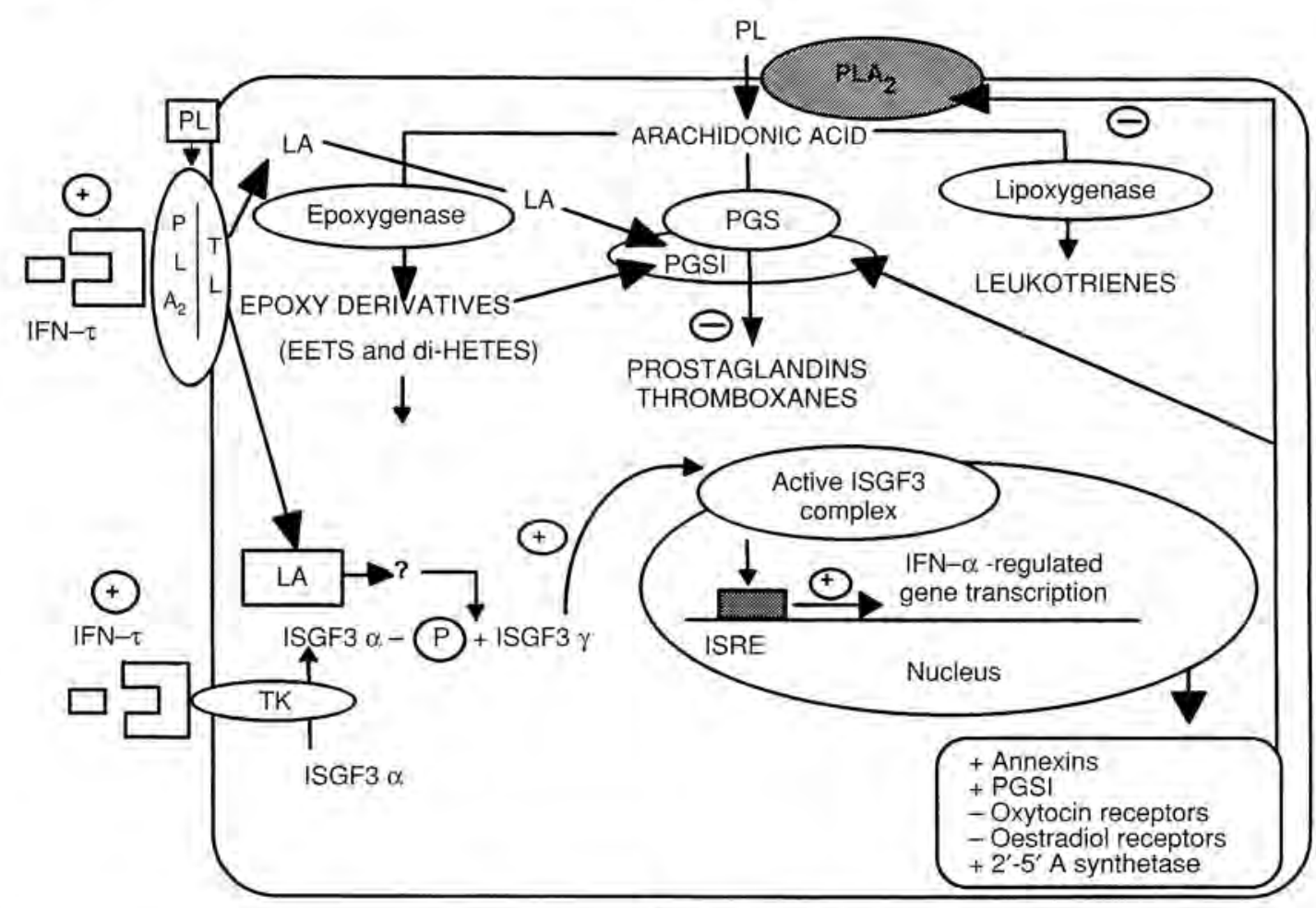

Plasma membrane

Fig. 6. Conceptual model for IFN- $\tau$ regulation of $\mathrm{PGF}_{2 v}$ secretion and gene expression leading to maintenance of the corpus luteum. IFN- $\tau$ acts through a signal transduction system for type I IFNs that involves binding to a common receptor and activation of an intracellular tyrosine kinase (TK). Subsequent phosphorylation of interferon-stimulated gene factors (ISGF3 $\alpha$ ) leads to their aggregation with ISGF3 $\gamma$. This active complex binds to interferon-stimulated response elements (ISRE) that regulate IFN- $u$ or IFN- $\tau$ gene transcription. IFN- $\tau$ regulated gene transcription may alter expression of such factors as annexins, PGS inhibitor system, oxytocin receptors, oestradiol receptors and $2^{\prime}-5^{\prime}$ A synthetase. Inhibition of prostaglandin endoperoxide $H$ synthase (PGS) due to IFN- $\tau$-induced mobilization of free linoleic acid (LA) causes a redirection of arachidonic acid metabolism from prostaglandins and leukotrienes to epoxy derivatives. Epoxy derivatives and linoleic acid act as a prostaglandin endoperoxide $\mathrm{H}$ synthase inhibitor (PGSI) and may have synergistic effects on interferon-stimulated gene expression through enhancing efficiency of phosphorylation by the intracellular tyrosine kinase activated via the IFN-t-receptor. Phospholipids (PL): phospholipase $\mathrm{A}_{2}\left(\mathrm{PLA}_{2}\right)$; triglyceride peptide (TL).

pregnancy (Tamby et al., I993), expression of the annexin family of proteins in response to olfN- $\tau$ warrants investigation. The annexins are proteins that are associated with an inhibition of PLA $\mathrm{A}_{2}$ activity and a decrease in $\mathrm{PGF}_{2 \mu}$ secretion because of their abilities to bind $\mathrm{Ca}^{2+}\left(\mathrm{Ca}^{2+}\right.$ is required for $\mathrm{PLA}{ }_{2}$ activity) and complex with phospholipids in a manner that alters phospholipid availability to $\mathrm{PLA}_{2}$ as a substrate (Davidson and Dennis, 1989).

Collectively, experimental observations involving IFN- $\tau$ as well as inferences drawn from responses to IFN- $\alpha$ in other species and cellular systems have led to the conceptual model depicted in Fig. 6 . This model accounts for the intracellular responses to IFN- $\tau$ that lead to a coordinated antiluteolytic effect that decreases. $\mathrm{PGF}_{2 a}$ secretion. This model is suggested only to provide a framework for future investigations into the antiluteolytic mechanisms that characterize the interaction between conceptus and endometrium. It is proposed that PGS is inhibited by IFN- $\tau$-induced mobilization of free linoleic acid (Fig. 6). This appears to be implemented by an enhancement in phospholipase or lipase activities

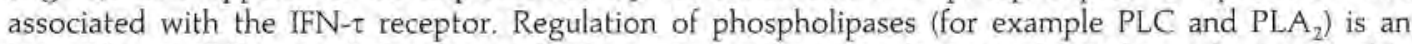
integral part of hormonal signal transduction systems (for example oxytocin) and may be involved in 
IFN- $\tau$ signalling. An increase in free linoleic acid causes a redirection of arachidonic acid metabolism from prostaglandins and leukotrienes to epoxy derivatives. This alteration in arachidonic acid metabolism is due to linoleic acid acting as a competitive inhibitor with arachidonic acid for PGS. Epoxy derivatives and linoleic acid have synergistic effects on interferon-stimulated gene expression through activation of transcription factors by tyrosine kinase (Fig. 6 ). Alterations in IFN- $\tau$-regulated gene expression lead to changes in certain intracellular gene products that potentially regulate prostaglandin secretion (increases in annexins, lipases $( \pm$ ) and inhibitory effects (directly or indirectly) on expression of oestradiol and oxytocin receptors (Fig. 6). In other cellular systems (for example mammary gland), linoleic and arachidonic acids are signal transducers that amplify receptor signal transduction systems for control of gene expression. Thus, an IFN- $\tau$-induced increase in linoleic acid could enhance the efficiency of IFN- $\tau$-induced gene expression regulated through other pathways and directly inhibit synthesis of $\mathrm{PGF}_{20}$. Subsequent alterations in oxytocin $(-)$ and oestradiol $(-)$ receptors plus the production of PLA inhibitors would result in a coordinated attenuation in the lytic secretion of $\mathrm{PGF}_{2 \alpha^{\circ}}$.

\section{Antiluteolytic Strategies to Improve Embryo Survival}

Supplementation of inseminated animals with exogenous IFN- $\tau$, during the period before the time of antiluteolytic signalling, is a means to compensate for potentially deficient secretion of IFN- $\tau$ by conceptuses that are behind in their development. Such a treatment would attenuate endometrial secretion of $\mathrm{PGF}_{2 a}$ and rescue a small percentage of normal embryos that might be developing at a slower rate. To date, amounts of available recombinant ovine and bovine IFN- $\tau$ have been insufficient to allow field testing of the potential fertility-enhancing effects of these proteins. An alternative approach has been to use recombinant bovine interferon- $\alpha_{1} I$ ( $r$ IfIFN- $a$ ), a protein with approximately $50 \%$ amino acid sequence similarity to bIFN- $\tau$ and oIFN- $\tau$. There is considerable evidence that $r b$ IFN- $\alpha$ can exert effects on the reproductive system that are characteristic of IFN- $\tau_{\text {; }}$ extension of corpus luteum lifespan (Plante et al, 1989), binding to endometrial receptors (Hansen et al., 1989; Stewart et al., 1987), alteration in endometrial protein secretion (Salamonsen et al., 1988), suppression of oxytocin-induced secretion of $\mathrm{PGF}_{2 a}$ in vivo (Plante et al. 1991), and induction of $2^{\prime}, 5^{\prime}$-oligoadenylate synthetase activity in endometrium (Barros ef al., 1991).

A series of fertility experiments in sheep with rbIFN- $\alpha$ have been promising (see review: Thatcher et al., 1994). Twice daily injections of rbIFN- $\alpha(2 \mathrm{mg})$ increased conception rates by 92 versus $76 \%$ (injection days 12 to 16 ); 80 versus $65 \%$ (injection days 11 to 18 ); 76 versus $69 \%$ (injection days 11 to 18). In contrast, administration of rbIFN- $\alpha$ to cattle decreased conception rates by about $10 \%$ regardless of whether a once daily injection (20 mg) was given between day 14 and day 17 , a single large dose $(40 \mathrm{mg})$ was given on day 13 , or a sequence of increasing doses $(0,01$ to $10 \mathrm{mg}$ ) was given between day 11 and day 19 after insemination (Thatcher et al., 1994). The rbIFN- $\alpha$ induced reduction in fertility was attributed to induced side effects of hyperthermia and acute decreases in plasma progesterone probably caused by decreased LH secretion.

The recombinant forms of bIFN- $\tau$ are likely to be effective at lower doses than is rbIFN $\alpha$ and this may reduce the potential for side effects. We have recently examined the effects of intramuscular injections of rbIFN- $\tau(0, I$ and $5 \mathrm{mg})$ on body temperature and plasma concentrations of progesterone in cattle (Meyer et al, 1994). The $5 \mathrm{mg}$ dose of rbiFN- $\tau$ had a similar effect to rbIFN- $\alpha$ in that a hyperthermic response of $40.3^{\circ} \mathrm{C}$ rectal temperature was observed $4 \mathrm{~b}$ after the injection. Paralleling the temporal increase and subsequent decline in rectal temperature to normal was a temporal decrease in plasma progesterone concentrations. However, the $1 \mathrm{mg}$ dose caused only a slight rise in rectal temperature to $39.5^{\circ} \mathrm{C}$ at $8 \mathrm{~h}$ after injection, and there was no alteration in plasma progesterone. This response is encouraging, and the antiluteolytic effect of a $1 \mathrm{mg}$ dose given once or twice a day needs to be examined. A sustained release delivery system may need to be developed to obtain effective delivery of sufficient rbIFN- $\tau$ to the uterus to prevent luteolysis but not induce detrimental side effects that compromise survival of the embryo.

In many of the studies carried out to document either in vivo (Helmer et al., 1989; Plante et al., 1989; Martal et al., 1990; Meyer et al., in press) or in vitro (Danet-Desnoyers et al., 1994) effects of rbIFN- $\alpha$, 
Plante C, Hansen PJ, Martinod S, Seigenthaler B, Thatcher WW, Pollard JW and Leslie MV (1989) Effect of intrauterine and intramuscular administration of recombinant bovine interferon $a_{1}$ on luteal lifespan in cattle Journal of Dairy Science $721859-1865$

Plante C, Thatcher WW and Hansen PJ (1991) Alteration of estrous cycle length, ovarian function and oxytocininduced release of prostaglandin $F_{2 a \alpha}$ by intrauterine and intramuscular administration of recombinant bovine interferon- $\alpha$ to cows Journal of Reproduction and Fertility 93 375-384

Roberts RM, Cross JC and Leman DW (1992) Interferons as hormones of pregnancy Endocrine Reviews 13 432-452

Rueda BR, Naivar KA, George EM, Austin KJ, Francis H and Hansen TR (1993) Recombinant interferon-? regulates secretion of two bovine endometrial proteins Joumal of Interferon Research 13 295-301

Salamonsen LA, Stuchberry SL, O'Grady CM, Godkin JD and Findlay JK (1988) Interferon- $\alpha$ mimics effects of ovine trophoblast protein-1 on prostaglandin and protein secretion by ovine endometrial cells in vitro Joural of Endocritology $117 \mathrm{R} 1-\mathrm{R} 4$

Salamonsen LA, Hampton AL, Clements JA and Findlay JK (1991) Regulation of gene expression and cellular localization of prostaglandin synthetase by oestrogen and progesterone in the ovine uterus Journal of Reproduction and Fertility 92 393-406

Schindler C, Shuai K. Prezioso VR and Darnell JE (1992) Interferon-dependent tyrosine phosphorylation of a latent cytoplasmic transcription factor Science $\mathbf{2 5 7}$ $809-813$

Short EC, Geisert RD, Helmer SD, Zavy MT and Fulton RW (1991) Expresșion of antiviral activity and induction of $2^{\prime}, 5^{\prime}$ oligoadenylate synthetase by conceptus secretory proteins enriched in bovine trophoblast protein-1 Biology of Reproduction 44 201-268

Silvia WJ and Raw RE (1993) Activity of phospholipase C and release of prostaglandin $F_{20}$ by endometrial tissue from ewes during the oestrous cycle and early pregnancy Joumal of Reproduction and Fertility 97 529-537

Silvia WJ, Ottobre JS and Inskeep EK (1984) Concentrations of prostaglandins $E_{20}, F_{211}$ and 6 -keto prostaglandin $F_{14}$ in the utero-ovarian venous plasma of nonpregnant and early pregnant ewes Biology of Reproduction 30 936-944

Silvia WJ, Lee J-S, Trammell DS, Hayes SH, Lowberger LI. and Brockman JA (1994) Cellular mechanisms mediating the stimulation of ovine endometrial secretion of prostaglandin $\mathrm{F}_{2 a}$ in response to oxytocin: role of phospholipase $\mathrm{C}$ and diacylglycerol Journal of Endocrinology 141 481-490

Sinith WL and Marnett LJ (1991) Prostaglandin endoperoxide synthase: structure and catalysis Biochimica et Biophysica Acta 1083 I-17

Spencer TE, Mirando MA, Ott TL, Ing NH and Bazer FW (1994) An explanation for the antiluteolytic effects of ovine interferon-tau (oIFN- $\tau$ ) Biology of Reproduction 50 (Supplement 1) 97 (Abstract)

Stewart HJ, McCann SHE, Barker PJ, Lee KE, Lamming GE and Flint APF (1987) Interferon sequence homology and receptor binding activity of ovine trophoblast antiluteolytic protein Joumal of Endocrinology 115 R13-R15

Tamby JP, Charpigny G. Reinaud P and Martal J (1993) Phospholipase $\mathrm{A} 2$ activity in endometrium from early pregnant and non-pregnant ewes Prostaglandins 46 407-415

Thatcher WW. Knickerbocker JI. Bartol FF, Bazer FW, Roberts RM and Drost M (1985) Matemal recognition of pregnancy in relation to the survival of transterred embryos: endocrine aspects Theriogenology 23 129-143

Thatcher WW, Bazer FW, Sharp DC and Roberts RM (1986) Interrelationships between uterus and conceptus to maintain corpus luteum function in early pregnancy: sheep, cattle, pigs and horses Joumal of Animal Science $\mathbf{6 2}$ (Supplement 2) 25-46́

Thatcher WW, Danet-Desnoyers G and Wetzels C (1992) Regulation of bovine endometrial prostaglandin secretion and the role of bovine trophoblast protein-1 complex Reproduction Fertility and Development 4 329-334

Thatcher WW, Staples CR, Danet-Desnoyers G, Oldick B and Schmitt E-P (1994) Embryo health and mortality in sheep and cattle Journal of Animal Science 72 16-30

Vallet Л, Barker PJ, Lamming GE, Skinner N and Huskisson NS (1991) A low molecular weight endometrial secretory protein which is increased by ovine trophoblast protein-I is a 32 microglobulin-like protejn Journal of Endocritaology 130 R 1-R4 